Research article

Open Access

\title{
Design of Experiment (DOE) Utilization to Develop a Simple and Robust Reversed-Phase HPLC Technique for Related Substances' Estimation of Omeprazole Formulations
}

\author{
Vayeda Chintan ManRanjan, Devendra Singh YadaV *, \\ Hitesh Amrutlal JogIA, Praful Lalitkumar CHAUHAN
}

Analytical Research and Development, Integrated Product Development, Dr. Reddy's Laboratories Ltd., Bachupally, Hyderabad-500 072, India.

* Corresponding author. E-mail: devendrasy@drreddys.com (D. S. Yadav)

Sci Pharm. 2013; 81: 1043-1056

doi:10.3797/scipharm.1306-06

Published: $\quad$ August $12^{\text {th }} 2013$

Accepted: $\quad$ August $12^{\text {th }} 2013$

Received: $\quad$ June $11^{\text {th }} 2013$

This article is available from: http://dx.doi.org/10.3797/scipharm.1306-06

(C) Manranjan et al.; licensee Österreichische Apotheker-Verlagsgesellschaft m. b. H., Vienna, Austria.

This is an Open Access article distributed under the terms of the Creative Commons Attribution License (http://creativecommons.org/licenses/by/3.0/), which permits unrestricted use, distribution, and reproduction in any medium, provided the original work is properly cited.

\begin{abstract}
A simple, fast, and sensitive reversed-phase HPLC method with UV detection was developed for the quantitation of omeprazole and its eleven related compounds (impurities) in pharmaceutical formulation using the Thermo Accucore C-18 (50 mm x $4.6 \mathrm{~mm}, 2.6 \mu \mathrm{m})$ column. The separation among all the compounds was achieved with a flow rate of $0.8 \mathrm{~mL} \mathrm{~min}{ }^{-1}$ employing a gradient program of mobile phase $\mathrm{A}[0.08 \mathrm{M}$ glycine buffer $\mathrm{pH}$ 9.0: acetonitrile; 95:05 (v/v)] and mobile phase B [acetonitrile: methanol; 65:35 (v/v)]. The chromatographic detection was carried out at a wavelength of $305 \mathrm{~nm}$. The method was validated for specificity, linearity, and recovery. The huskiness of the method was determined prior to validation using the Design of Experiments (DOE). The ANOVA analysis of DOE with a 95\% confidence interval (CI) confirmed the buffer $\mathrm{pH}$ of mobile phase $\mathrm{A}(\mathrm{p}<0.0001)$ and column temperature $(p<0.0001)$ as significant Critical Method Parameters (CMPs).
\end{abstract}

\section{Keywords}

DOE • HPLC/UPLC • Compatible • Related Substances • Anova • Method development • Chromatography 


\section{Introduction}

Over the last few years, there seems to have been a marked strengthening of the requirements for the isolation and separation of impurities resulting from active pharmaceutical ingredients by regulatory agencies [1]. As a consequence, the analytical technology for impurity analysis has improved beyond the traditional chromatographic and spectroscopic methods [2].

Omeprazole, 5-methoxy-2-\{[(4-methoxy-3,5-dimethylpyridin-2-yl)methyl]sulfinyl\}-1H-benzimidazole, is one of the most frequently prescribed drugs in patients with gastroesophageal reflux disease (GERD) [3]. Pharmacopoeial monographs and literature are available for the stability-indicating HPLC and UPLC method for omeprazole/ esomeprazole, in which separation was achieved among the drug and a maximum of around seven related compounds (impurities) [4-8].

However, omeprazole has more than seven related impurities (including pharmacopoeial Inon-pharmacopoeial) which needs to be separated in a chromatographic run (Fig. 1). Moreover, some laboratories which are governed by respective national regulatory agencies do not encourage the use of UPLC as it is not commonly available. Thus, to subdue this issue, the idea was to develop an HPLC/UPLC compatible method, which is a formidable task.

The method was developed using the one-factor-at-a-time (OFAT) approach, where one variable changes sequentially until a suitable method is shaped, which is an old approach. This type of method development provides limited understanding of a method's capabilities and robustness. A quality-by-design approach uses statistical Design of Experiments to develop a rugged method with 'design space'. The design space defines the experimental region in which changes to method parameters will not significantly affect the quality and results of the method. This approach strengthens the robustness of the method being developed $[9,10]$. Sabrina Flor et al. exploited the experimental design concept to assess the ruggedness of the stability-indicating method for omeprazole, only considering the closely eluting impurity to the main peak [11].

In this work we adopted the QbD principle to develop the HPLC/UPLC-compatible stabilityindicating method for omeprazole's Dual Delayed Release (DDR) to attain the desired separation. The Accucore column packed with pellicular particles was explored to achieve the desired separation among omeprazole and its related impurities with the reduced run time.

\section{Experimental}

\section{Chemicals and Reagents}

All standards and test samples were supplied by Dr. Reddy's Laboratories Limited, Hyderabad, India; i.e. omeprazole, Impurity-1 (1-(5-methoxy-1H-benzimidazol-2-yl)-3,5dimethyl-4-oxo-1,4-dihydropyridine-2-carboxylic acid), Impurity-2 (5-methoxy-1H-benzimidazole-2-thiol), Impurity-3 (2-[(5-methoxy-1H-benzimidazol-2-yl)methyl]-3,5-dimethylpyridin-4(1H)-one), Impurity-4 (5-methoxy-2-\{[(4-methoxy-3,5-dimethyl-1-oxidopyridin-2yl)methyl $]$ sulfinyl\}-1H-benzimidazole), Impurity-5 (2-\{[(5-methoxy-1H-benzimidazol-2-yl)sulfanyl]methyl\}-3,5-dimethylpyridin-4-ol), Impurity-6 (5-methoxy-2-\{[(4-methoxy-3,5-di 


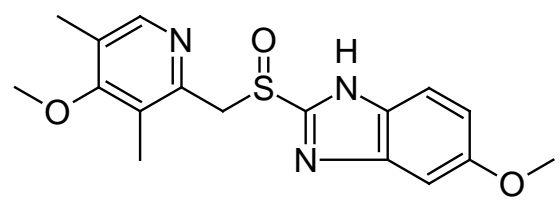

Omeprazole

Log P: 2.17<smiles>COc1ccc2[nH]c(-n3cc(C)c(=O)c(C)c3C(=O)O)nc2c1</smiles>

Impurity-1 Log P: 1.16<smiles>COc1ccc2[nH]c(S(=O)Cc3c(C)c(OC)c(C)c[n+]3[O-])nc2c1</smiles>

Impurity-4 Log P: not determined<smiles>COc1ccc2[nH]c(S(=O)Cc3ncc(C)cc3C)nc2c1</smiles>
Impurity-7 Log P: 2.29<smiles>COc1ccc2[nH]c(S)nc2c1</smiles>

Impurity-2 Log P: 1.85<smiles>COc1ccc2[nH]c(SCc3ncc(C)c(O)c3C)nc2c1</smiles>
Impurity-5 Log P: 3.51<smiles>COc1ccc2c(c1)nc(S(=O)Cc1ncc(C)c(OC)c1C)n2C</smiles>

Impurity-8 Log P: 2.40<smiles>COc1ccc2[nH]c(Cc3[nH]cc(C)c(=O)c3C)nc2c1</smiles>

Impurity-3 Log P: 1.16<smiles>COc1ccc2[nH]c(S(=O)(=O)Cc3ncc(C)c(OC)c3C)nc2c1</smiles>

Impurity-6 Log P: 2.21<smiles>COc1ccc2[nH]c(SCc3ncc(C)c(OC)c3C)nc2c1</smiles>

Impurity-9 Log P: 3.77

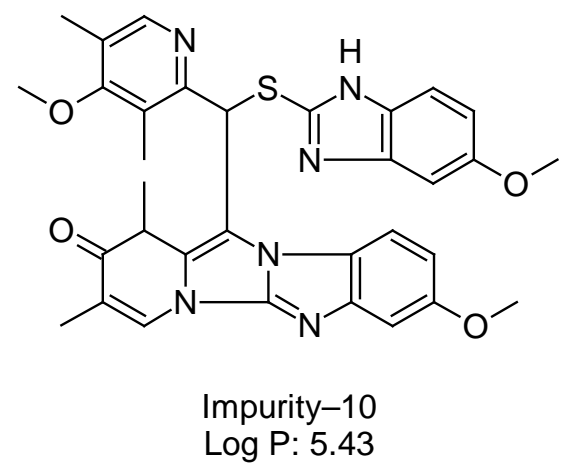

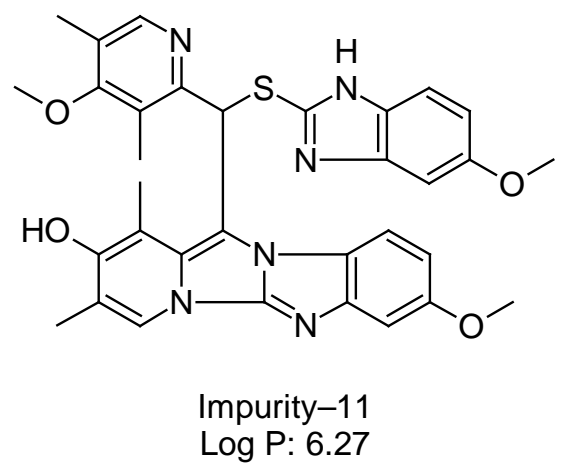

Fig. 1. Structure of omeprazole and all related compounds with Log $P$ values 
methylpyridin-2-yl)methyl]sulfonyl\}-1H-benzimidazole), Impurity-7 (2-\{[(3,5-dimethylpyridin2-yl)methyl]sulfinyl\}-5-methoxy-1H-benzimidazole), Impurity-8 (5-methoxy-2-\{[(4-methoxy3,5-dimethylpyridin-2-yl)methyl]sulfinyl\}-1-methyl-1H-benzimidazole), Impurity-9 (5-methoxy-2-\{[(4-methoxy-3,5-dimethylpyridin-2-yl)methyl]sulfanyl\}-1H-benzimidazole), Impurity10 (8-methoxy-12-\{[(5-methoxy-1H-benzimidazol-2-yl)sulfanyl](4-methoxy-3,5-dimethylpyridin-2-yl)methyl\}-1,3-dimethylpyrido[1',2':3,4]imidazo[1,2-a]benzimidazol-2(1H)-one), Impurity-11 (8-methoxy-12-\{[(5-methoxy-1H-benzimidazol-2-yl)sulfanyl](4-methoxy-3,5-dimethylpyridin-2-yl)methyl\}-1,3-dimethylpyrido[1',2':3,4]imidazo[1,2-a]benzimidazol-2-ol). HPLC grade acetonitrile, methanol, and analytical grade glycine, borax, and phosphoric acid were procured from Merck, Darmstadt, Germany. Water was obtained by using the Millipore Milli-Q Plus water purification system.

\section{Equipment}

The HPLC (Agilent, USA) used consisted of a quaternary solvent manager, a sample manager, and a UV-Visible multiple wavelength detector. The output signal was monitored and processed using Empower-2 software.

The UPLC (Waters, USA) used consisted of a quaternary solvent manager, a sample manager, and a photodiode array wavelength detector. The output signal was monitored and processed using Empower 2 software.

\section{Briefly about the Formulation}

The omeprazole DDR formulation is a mixture of delayed (DR) and extended (ER) release pellets [12], where the solubility and dispersion of the DR part is $\mathrm{pH}$-dependent; while the ER part is $\mathrm{pH}$-independent. The DR part of the formulation is likely to facilitate a loading dose of the drug, while the ER part is prone to maintain the concentration of the drug.

\section{Chromatographic Conditions}

The Thermo Scientific Accucore C-18 $(50 \mathrm{~mm} \times 4.6 \mathrm{~mm}, 2.6 \mu \mathrm{m})$ was used as the chromatographic column. The separations among all the compounds were achieved with a flow rate of $0.8 \mathrm{~mL} \mathrm{~min}^{-1}$ using a gradient program of mobile phase $A$ and mobile phase $B$ with a $5 \mu \mathrm{L}$ injection volume. Where mobile phase $\mathrm{A}$ consisted of a $0.08 \mathrm{M}$ glycine $(\mathrm{pH} 9.0)$ buffer and acetonitrile in a 95:05 (v/v) ratio, mobile phase B was prepared by mixing acetonitrile and methanol in the ratio of $65: 35(\mathrm{v} / \mathrm{v})$, respectively. The HPLC gradient program was set as: time (min) vs. \% mobile phase A: 0/100, 1/100, 11.8/92, 23.3/75, $30.5 / 60,37.7 / 30,43 / 30,45 / 100$, and 50/100. The column temperature was maintained at $30^{\circ} \mathrm{C}$ and the detection was monitored at $305 \mathrm{~nm}$ wavelength. A mixture of $0.01 \mathrm{M}$ borax and ethanol in the proportion of 80:20 (v/v) was used as a solvent/diluent.

\section{Preparation of Standard Solution}

A stock solution of omeprazole standard $\left(60 \mu \mathrm{g} \mathrm{mL}^{-1}\right)$ was prepared by dissolving an accurately weighed amount of omeprazole standard in diluent. The final concentration of the standard was kept at $1.8 \mu \mathrm{g} \mathrm{mL}^{-1}$ by diluting an appropriate volume of stock solution with diluent. 


\section{Preparation of System Suitability Solution}

A suitable amount of omeprazole and nine other impurities (Impurity-1 to Impurity-9) were dissolved in diluent to prepare a mixture that contained $600 \mu \mathrm{g} \mathrm{mL}^{-1}$ of omeprazole and $1.8 \mu \mathrm{g} \mathrm{mL}^{-1}$ of each impurity.

\section{Preparation of the Test}

Omeprazole pellets equivalent to $600 \mathrm{mg}$ of omeprazole were dissolved in diluent by sonication for 30 minutes with intermittent shaking. The final concentration of the test was maintained at $600 \mu \mathrm{g} \mathrm{mL}-1$ using diluent. The sample solution was filtered through a $0.45 \mu \mathrm{m}$ PVDF hydrophilic membrane filter. Likewise, one more sample was prepared with omeprazole pellets and diluent, in which all nine impurities (Impurity-1 to Impurity-9) were spiked at $0.5 \%$ of the analyte concentration.

\section{Experimental Design}

Utilizing the two-level full factorial design options, the experimental design was created in Design Expert V8 software for Critical Method Parameters (CMPs). Evaluation of the selected (Tab. 3) Critical Quality Attributes (CQAs) was carried out by ANOVA statistics for experimental design.

\section{Results and Discussion}

\section{Method Optimization}

During the stressed and stability studies it was found that the in-house developed omeprazole formulation generated eleven impurities, out of which five impurities (Impurities-2, 4, 6, 7, and 9) were pharmacopoeial, while the other six impurities (Impurities-1, 3, 5, 8, 10, and 11) were non-pharmacopoeial (Fig. 1) [13, 14]. Structure elucidation and characterization were carried out in-house for six non-pharmacopoeial impurities (data not published).

The purpose of the work was to develop a HPLC/UPLC-compatible method capable of separating omeprazole from its eleven related impurities in a single chromatographic run. The structure and Log P values (obtained using ChemDraw V12) of omeprazole and its impurities (Fig. 1) indicate that all compounds have similar functional groups, but are dissimilar in polarity. Therefore, a buffer salt capable of reacting reciprocally is required for buffer preparation. The amphoteric characteristics of the buffer salt, glycine, which increases the durability of the silica-based reversed-phase column [15], was selected for the buffer preparation of mobile phase $\mathrm{A}$. The $\mathrm{pH}$ of the mobile phase $\mathrm{A}$ buffer was selected based on the stability of omeprazole in basic solution [16]. The desired separation of all impurities with the HPLC method using a traditional C18 column $(100 \mathrm{~mm} \times 4.6 \mathrm{~mm}$, $5 \mu \mathrm{m}$ ) was achieved within $120 \mathrm{~min}$, hence, the target was to develop a compatible method with a shorter run time. Development was initiated using only small length columns i.e. Waters: X-Bridge C18 Column $(50 \mathrm{~mm} \times 4.6 \mathrm{~mm}, 5 \mu \mathrm{m})$ with a flow rate that varies from $1.0 \mathrm{~mL} \mathrm{m^{-1 }}$ to $0.8 \mathrm{~mL} \mathrm{~min}^{-1}$ using a gradient program of mobile phase $A$ and mobile phase $B$. The perceptible separation was not achieved using a Waters X-Bridge column among the drug peak and related impurities. Consequently, the stationary phase was replaced with a column packed with pellicular particles (Agilent Poroshell), which are not totally porous particles, but rather they have a solid core and a thin porous outer layer. The 
thin porous layer of these particles allows very rapid access of molecules to interactive surfaces within the porous structure. The result is that high mobile phase velocity can be used for very fast separations with good column efficiency [17-19]. Eventually, the first satisfactory chromatographic separation was achieved among omeprazole and its related compounds using the Agilent Poroshell $120 \mathrm{EC}-\mathrm{C} 18(50 \mathrm{~mm} \times 4.6 \mathrm{~mm}, 2.7 \mu \mathrm{m})$ column

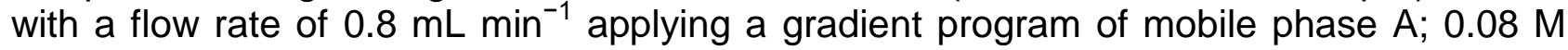
glycine ( $\mathrm{pH}$ 9.0) buffer: acetonitrile 95:05 (v/v) and mobile phase $\mathrm{B}$; acetonitrile: methanol 65:35 (v/v), respectively. However, the Agilent column only has a viable pH range of 2-9 [18]. Because of this, the column was substituted by the Thermo Accucore C-18 $(50 \mathrm{~mm} \times$ $4.6 \mathrm{~mm}, 2.6 \mu \mathrm{m}$ ) column, packed with similar pellicular stationary phases and additionally, has a higher $\mathrm{pH}$ working range (i.e. $\mathrm{pH}$ 2-11) [19]. Separation among all compounds was achieved by using a gradient program with a slight modification of mobile phase $A$ with respect to time i.e. min/\% of mobile phase A: $0 / 100,1 / 100,11.8 / 92,23.3 / 75,30.5 / 60$, $37.7 / 30,43 / 30,45 / 100$, and 50/100.

Omeprazole and its related impurities were well-separated in the optimized chromatographic conditions \{Fig. 2 (A), (B), (C), and (D)\} on the HPLC and UPLC. The retention times of all impurities was confirmed by injecting individual impurity solutions. Impurity-10 and Impurity-11 were removed from the system suitability due to the unavailability of the impurities' standards.

Likewise, the relative response factor (RRF) and linearity were determined for the eight impurities instead of the eleven impurities due to the unavailability of the Impurity-3 standard in sufficient quantity.

\section{Specificity}

The specificity of the chromatographic method was verified using a placebo (all formulation substances excluding the active one) instead of the actual formulation. No interference was observed either at the retention time of the impurities or at the retention time of omeprazole. This indicates that the method is specific and selective for omeprazole and its related compounds' analysis $\{$ Fig. 2(B)\}.

\section{Linearity and Recovery}

The results of retention time, relative retention time, and resolution from the adjacent peak, peak tailing, and RRFs are captured in Tab. 1. Linearity solutions for the related compounds and omeprazole were prepared by serial dilution of the impurity stock solutions and the omeprazole stock solution. Five different concentrations between $0.6 \mu \mathrm{g}$ $\mathrm{mL}^{-1}\left(0.1 \%\right.$ of the test preparation) and $6.0 \mu \mathrm{g} \mathrm{mL}^{-1}$ (1.0\% of test preparation) were prepared for linearity. The maximum permissible limit for all omeprazole-related compounds is $0.3 \%$ (based on the dose value) for an analyte concentration of $600 \mu \mathrm{g}$ $\mathrm{mL}^{-1}$. 


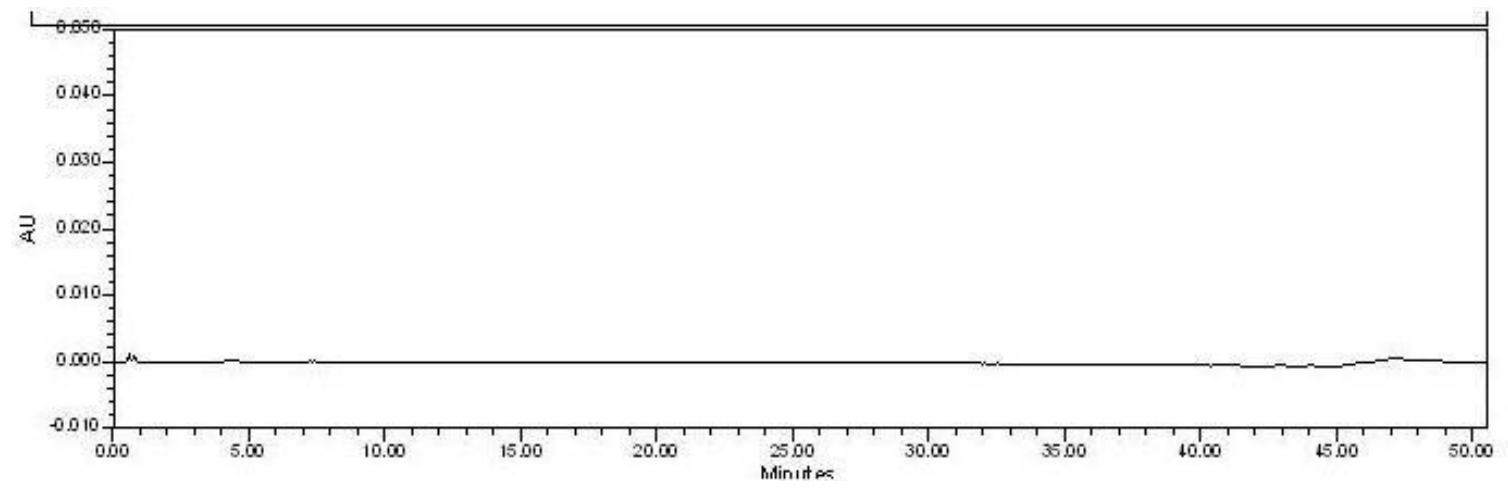

Fig. 2(A). Specimen Chromatogram of Placebo injected in HPLC

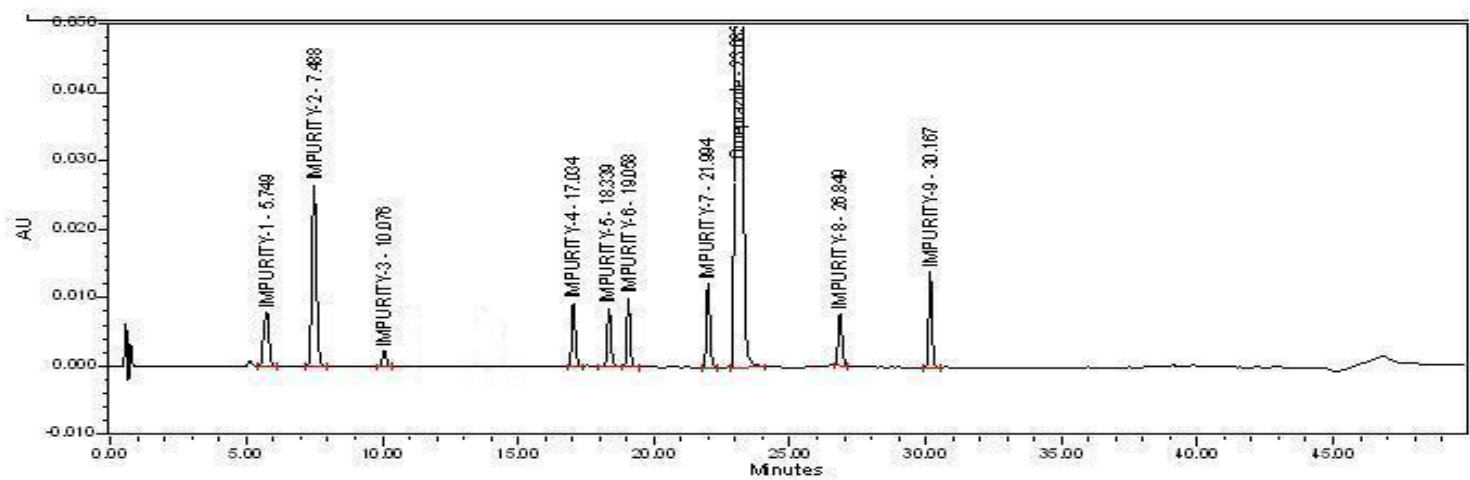

Fig. 2(B). Specimen Chromatogram of System Suitability injected in HPLC

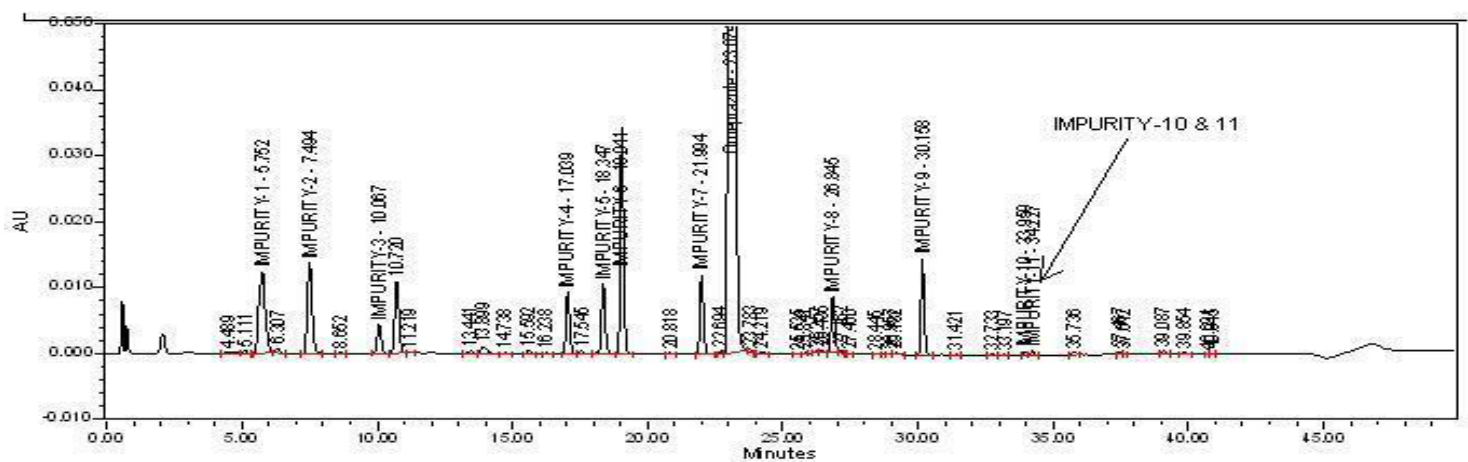

Fig. 2(C). Specimen Chromatogram of Spiked Test injected in HPLC

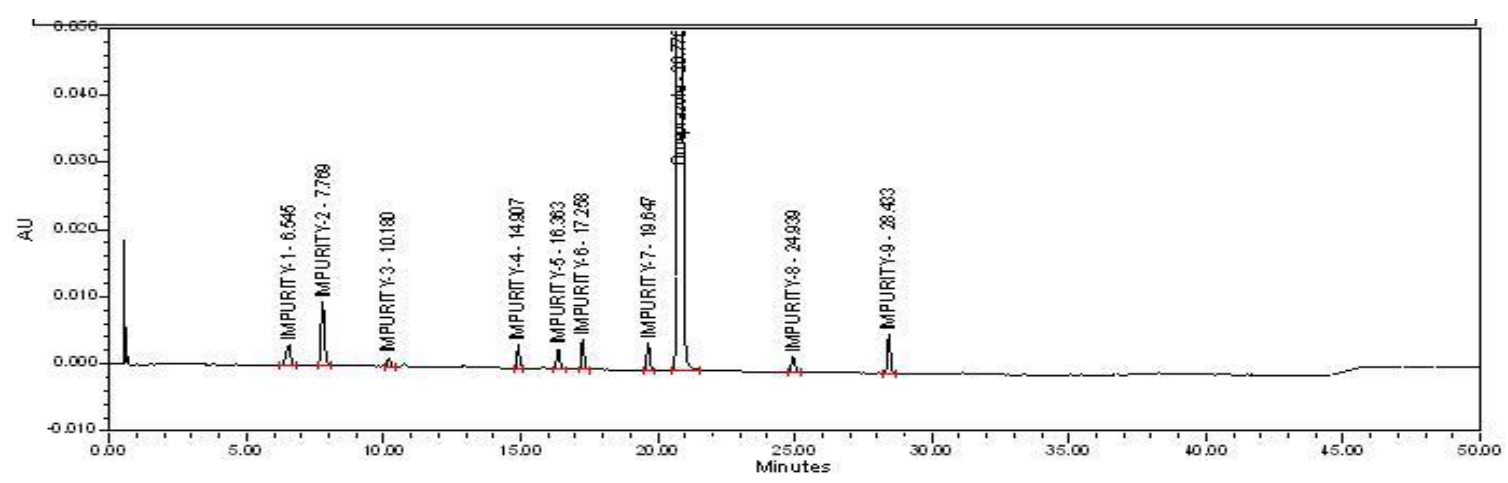

Fig. 2(D). Specimen Chromatogram of System Suitability injected in UPLC 
Tab. 1. Retention Time, Relative Retention Time, Resolution from adjacent peak, peak tailing, and RRF for final chromatographic method.

\begin{tabular}{|c|c|c|c|c|c|}
\hline $\begin{array}{l}\text { Compound } \\
\text { Name }\end{array}$ & $\begin{array}{l}\text { Retention } \\
\text { Time }\end{array}$ & $\begin{array}{c}\text { Relative } \\
\text { Retention Time }\end{array}$ & Resolution & $\begin{array}{l}\text { Tailing } \\
\text { Factor }\end{array}$ & RRF \\
\hline Omeprazole & 23.085 & $N A^{*}$ & About 4.5 & About 1.1 & \\
\hline Impurity-1 & 5.749 & About 0.25 & $N A^{*}$ & About 1.1 & 1.24 \\
\hline Impurity-2 & 7.490 & About 0.33 & About 5.3 & About 1.1 & 3.09 \\
\hline Impurity-3 & 10.078 & About 0.43 & About 8.5 & About 1.1 & ND* \\
\hline Impurity-4 & 17.034 & About 0.74 & About 26.4 & About 1.1 & 0.94 \\
\hline Impurity-5 & 18.339 & About 0.80 & About 5.1 & About 1.1 & 0.98 \\
\hline Impurity-6 & 19.058 & About 0.82 & About 2.8 & About 1.1 & 1.01 \\
\hline Impurity-7 & 21.994 & About 0.95 & About 12.8 & About 1.1 & 1.15 \\
\hline Impurity-8 & 26.849 & About 1.16 & About 14.4 & About 1.1 & 0.82 \\
\hline Impurity-9 & 30.167 & About 1.31 & About 13.2 & About 1.1 & 1.07 \\
\hline Impurity-10 & 33.921 & About 1.47 & About 4.5 & About 1.1 & ND* \\
\hline Impurity-11 & 34.189 & About 1.48 & About 1.5 & About 1.1 & ND* \\
\hline
\end{tabular}

Tab. 2. Linearity and recovery in final chromatographic method

\begin{tabular}{|c|c|c|c|c|c|c|}
\hline $\begin{array}{l}\text { Compound } \\
\text { Name }\end{array}$ & Slope & Intercept & $\begin{array}{l}\text { Correlation } \\
\text { coefficient }\end{array}$ & Bias & $\begin{array}{l}\text { Recovery } \\
\text { at } 0.3 \%\end{array}$ & $\begin{array}{c}\text { Recovery } \\
\text { at } 0.6 \%\end{array}$ \\
\hline Omeprazole & 15503.0 & 359.59 & 0.9999 & 0.76 & $100 \%$ & $100 \%$ \\
\hline Impurity-1 & 19267.4 & 503.42 & 0.9999 & 0.88 & $91 \%$ & $92 \%$ \\
\hline Impurity-2 & 47909.1 & 1596.08 & 0.9998 & 1.09 & $95 \%$ & $94 \%$ \\
\hline Impurity-3 & ND & ND & ND & ND & ND & ND \\
\hline Impurity-4 & 14574.4 & -8.46 & 0.9999 & -0.02 & $95 \%$ & $95 \%$ \\
\hline Impurity-5 & 15251.5 & -80.75 & 0.9999 & -0.18 & $91 \%$ & $91 \%$ \\
\hline Impurity-6 & 15723.5 & 958.05 & 0.9996 & 1.96 & $97 \%$ & $97 \%$ \\
\hline Impurity-7 & 17866.7 & 301.95 & 1.0000 & 0.56 & $95 \%$ & $96 \%$ \\
\hline Impurity-8 & 12636.2 & 723.12 & 0.9999 & 1.84 & $97 \%$ & $97 \%$ \\
\hline Impurity-9 & 16614.1 & 289.97 & 1.0000 & 0.58 & $94 \%$ & $95 \%$ \\
\hline Impurity-10 & ND* & ND* & ND* & ND* & ND* & ND* \\
\hline Impurity-11 & ND* & ND* & ND* & ND* & $N D^{*}$ & ND* \\
\hline
\end{tabular}

The correlation coefficients, slopes, and y-intercepts of the calibration plots are reported (Tab. 2) for the eight related compounds. The correlation coefficient values are $>0.998$ for all the components and the y-intercept bias is within $\pm 2.0 \%$ of $100 \%$ linearity response (Tab. 2). These results indicate that the method is linear up to the specified range of concentrations. The accuracy study of related compounds was performed at $0.3 \%$ and $0.6 \%$ levels of the analyte concentration $\left(600 \mu \mathrm{g} \mathrm{mL}^{-1}\right)$ (Tab. 2). 


\section{Experimental Design}

The ability of a chromatographic method to successfully separate, identify, and quantitate species was determined by a number of factors, many of which are in the control of the experimenter. Attempting to discover the importance of these factors with respect to the response, the experimental design/Design of Experiments (DOE) gives a powerful suite of statistical methodology, which is capable of estimating the effects of each factor in combination as well as alone. Based on the experience of development, flow rate, $\mathrm{pH}$ of the glycine buffer used to prepare mobile phase $A, \%$ of acetonitrile in mobile phase $B$, and the column temperature were identified as Critical Method Parameters (CMPs) for DOE to evaluate the huskiness of the method (Tab. 3).

Tab. 3. CMP, CQA, and QTMP

\begin{tabular}{|c|c|c|c|c|}
\hline \multicolumn{5}{|c|}{ Omeprazole DDR Stability-Indicating Analysis Method } \\
\hline \multirow[t]{2}{*}{$\begin{array}{c}\text { CMP(Critical } \\
\text { Method Parameter) }\end{array}$} & \multicolumn{2}{|c|}{$\begin{array}{c}\text { Range of each } \\
\text { parameters used for } \\
\text { DOE }\end{array}$} & \multirow{2}{*}{$\begin{array}{c}\begin{array}{c}\text { QTMP(Quality } \\
\text { Target Method } \\
\text { Profile) }\end{array} \\
\text { Targeted QTMP }\end{array}$} & \multirow[t]{2}{*}{$\begin{array}{c}\text { CQA (Critical } \\
\text { Quality Attribute) }\end{array}$} \\
\hline & Low & High & & \\
\hline A) Flow rate & $0.6 \mathrm{~mL} / \mathrm{min}$ & $1.0 \mathrm{~mL} / \mathrm{min}$ & \multirow{5}{*}{$\begin{array}{l}\text { Resolution } \\
\text { should be } \\
\text { not less } \\
\text { than } 2\end{array}$} & \\
\hline B) $\mathrm{pH}$ of glycine & & & & Resolution \\
\hline $\begin{array}{l}\text { buffer used to } \\
\text { prepare mobile } \\
\text { phase-A }\end{array}$ & $\mathrm{pH} 8.6$ & $\mathrm{pH} 9.4$ & & $\begin{array}{l}\text { between Impurity-1 } \\
\text { and Impurity-2 }\end{array}$ \\
\hline $\begin{array}{l}\text { C) } \% \text { of Acetonitrile } \\
\text { in mobile phase-B }\end{array}$ & $45 \%$ & $85 \%$ & & \multirow{2}{*}{$\begin{array}{l}\text { Resolution } \\
\text { between Impurity-5 } \\
\text { and Impurity-6 }\end{array}$} \\
\hline $\begin{array}{l}\text { D) Column Oven } \\
\text { Temperature }\end{array}$ & $20^{\circ} \mathrm{C}$ & $40^{\circ} \mathrm{C}$ & & \\
\hline
\end{tabular}

The resolutions between Impurity-1 and Impurity-2 (Response-1) as well between Impurity-5 and Impurity-6 (Response-2) were found to be critical, as they get affected by selected CMPs. Henceforth, these two responses were selected as Critical Quality Attributes (CQAs) to assess the effect of CMPs (Tab. 3). Two-level full-factorial DOE, with three centre points, were generated using Design Expert software $(n=19)$. The ANOVA analysis with a 95\% confidence interval $(\mathrm{Cl})$ for the chosen responses of the DOE reveals the existence of curvature, which indicates a systematic contribution of the independent factor that is not accounted by the model. Hence, the design was orthogonally augmented with two centre points and eight axial points. (Total $n=29$ ).

Again, the responses were analyzed by ANOVA with a $95 \% \mathrm{Cl}$. The DOE results identified the column temperature and $\mathrm{pH}$ as the most critical parameters $(\mathrm{p}<0.05)$ for the selected responses (Tab. 4). The perturbation plot $\{\mathrm{Fig} .3(\mathrm{~A})$ and $(\mathrm{C})\}$ displays the effect of all the factors at a particular point in the design space for the selected responses. 


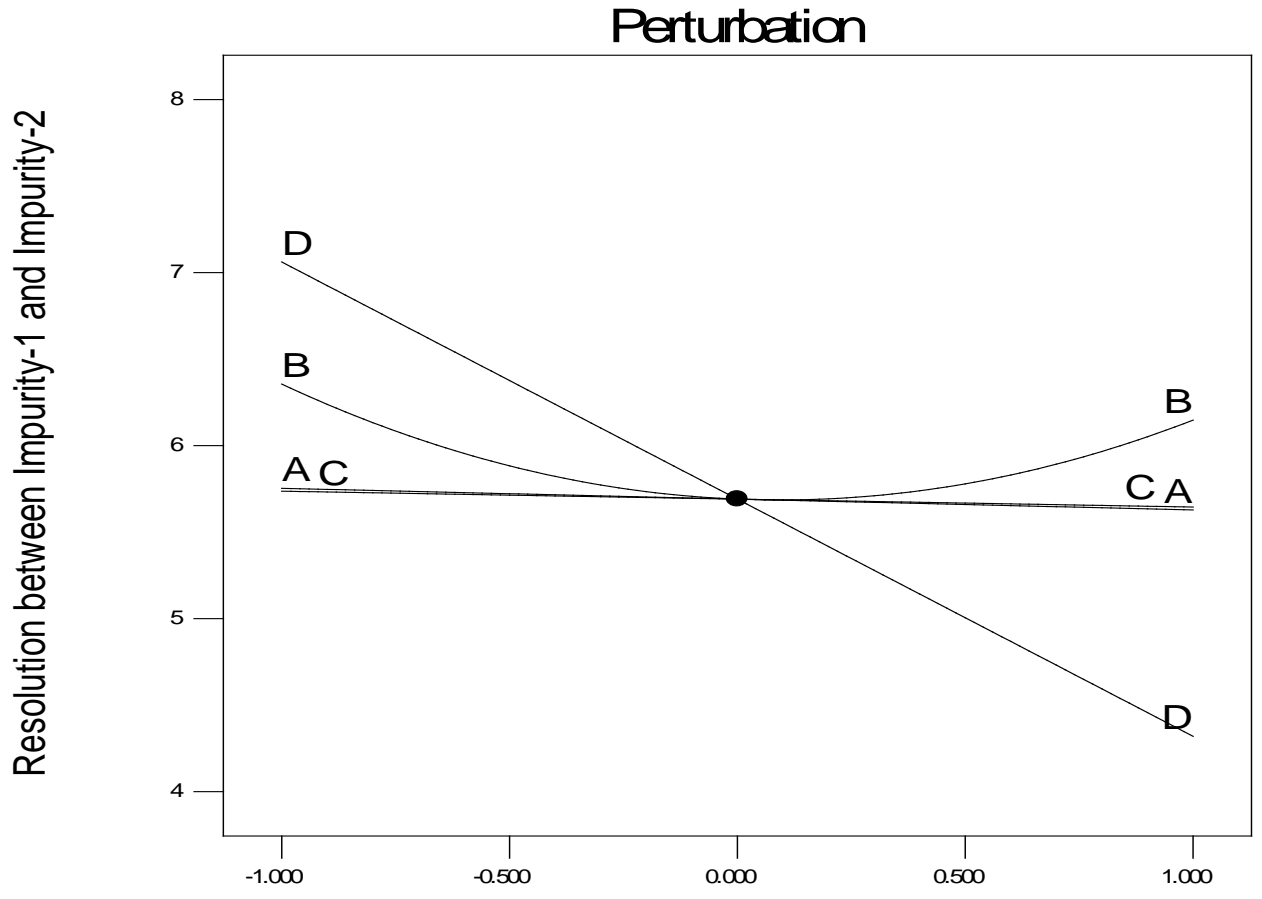

Deviation from Reference Point (Coded Units)

Fig. 3(A). Perturbation graph for Response-1

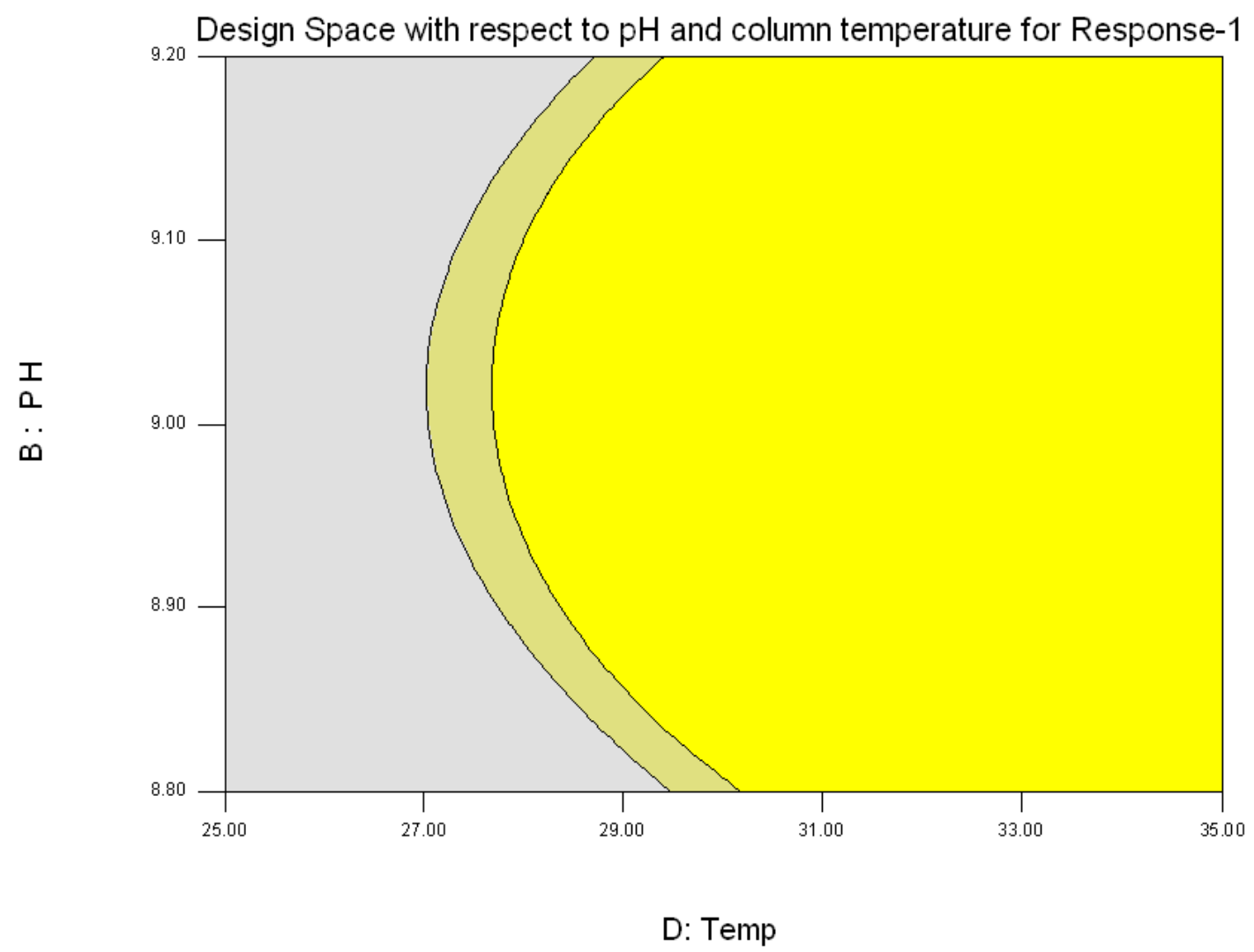

Fig. 3(B). Design Space (Yellow color) for Response-1 


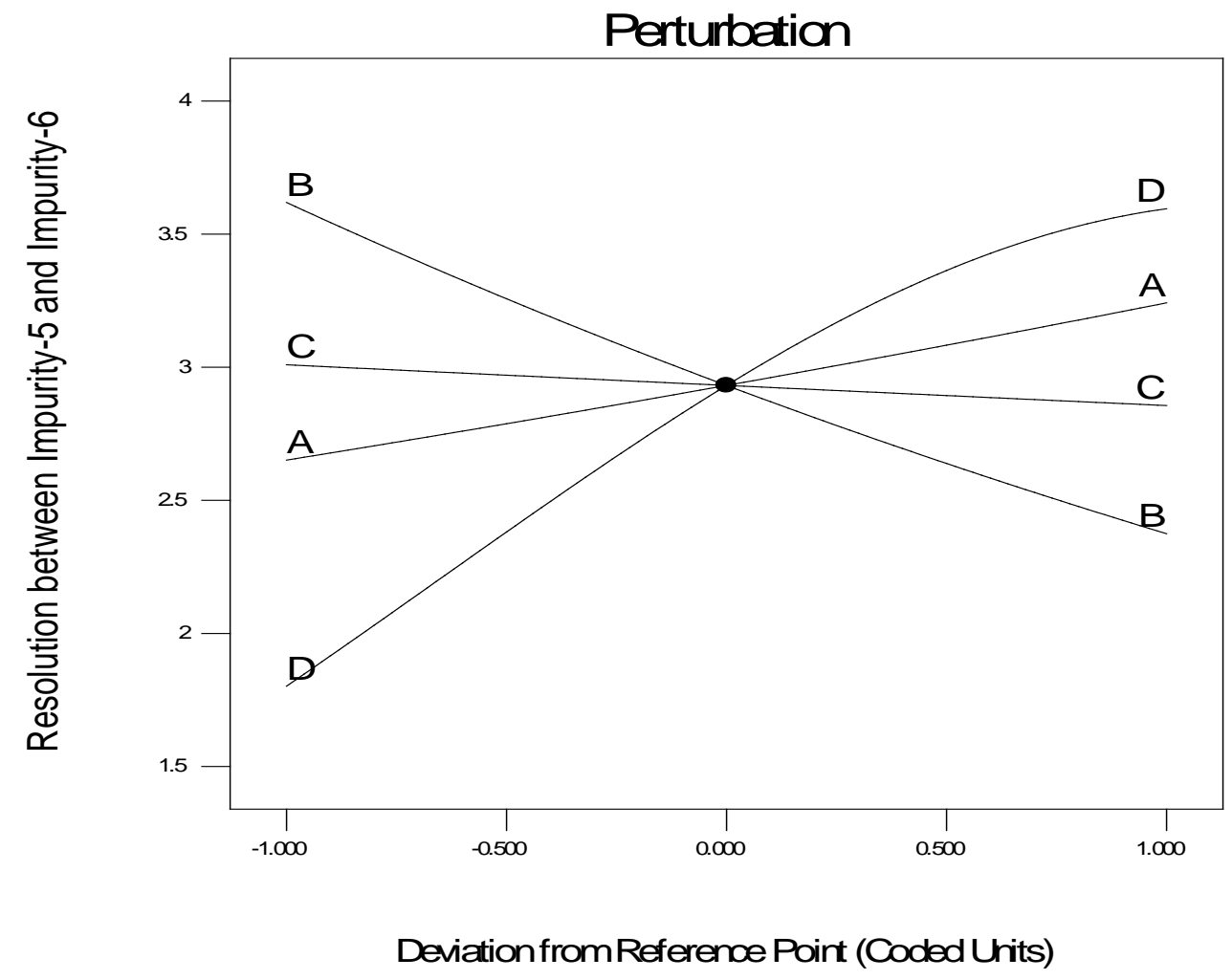

Fig. 3(C). Perturbation graph for Response-2

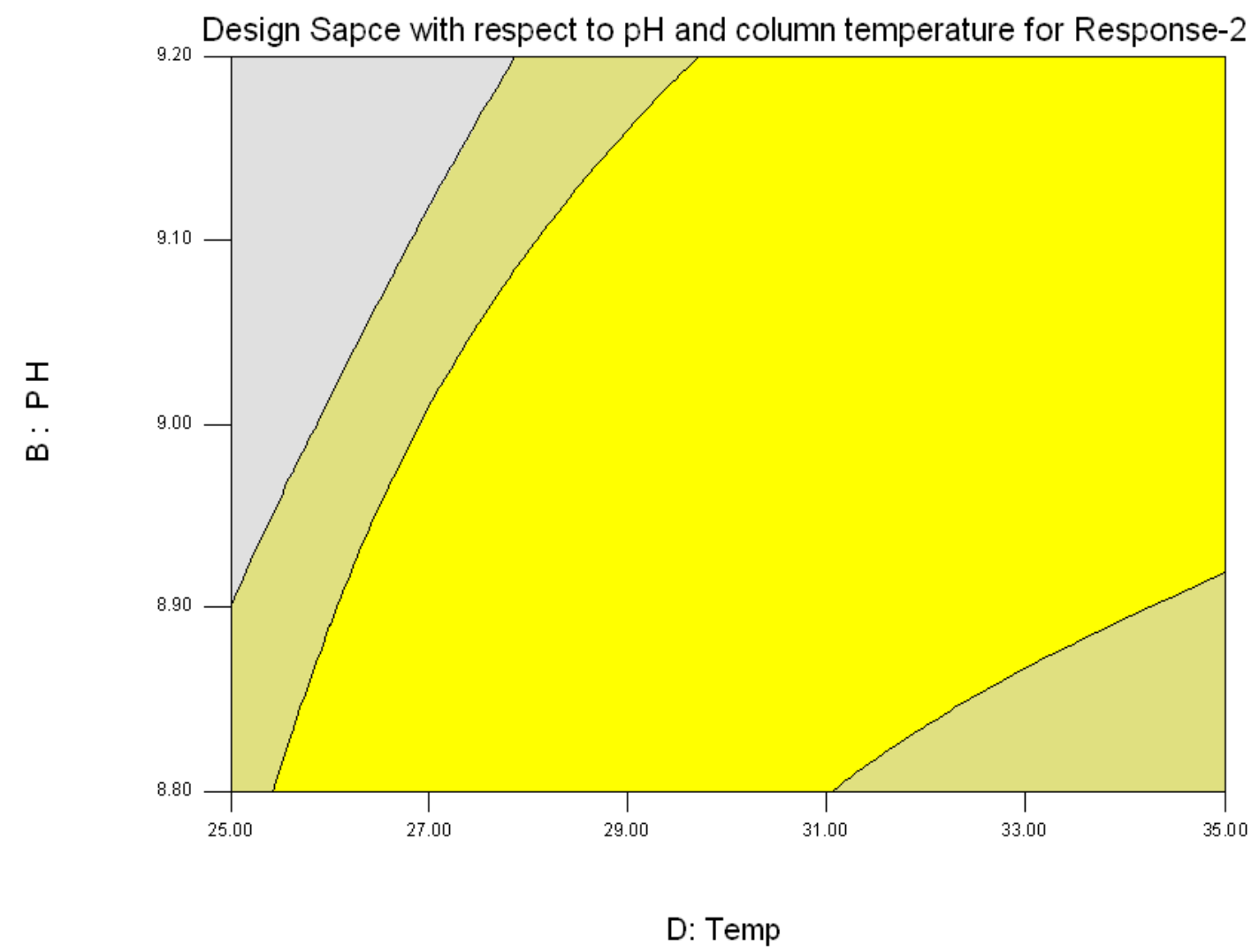

Fig. 3(D). Design Space (Yellow color) for Response-2 
Tab. 4. ANOVA analysis

\begin{tabular}{|c|c|c|c|c|c|}
\hline \multirow{2}{*}{$\begin{array}{l}\text { Parameters } \\
\text { selected for } \\
\text { ANOVA } \\
\text { Analysis }\end{array}$} & \multicolumn{2}{|c|}{$\begin{array}{c}\text { Resolution between } \\
\text { Impurity-1 and Impurity-2 }\end{array}$} & \multicolumn{2}{|c|}{$\begin{array}{l}\text { Resolution between } \\
\text { Impurity-5 and Impurity- } 6\end{array}$} & \multirow[t]{2}{*}{$\begin{array}{l}\text { Acceptance } \\
\text { criteria }\end{array}$} \\
\hline & $\begin{array}{l}p \text { Value for } \\
\text { ANOVA }\end{array}$ & Significance & $\begin{array}{l}p \text { Value for } \\
\text { ANOVA }\end{array}$ & Significance & \\
\hline A-Flow & 0.4630 & Not significant & 0.0833 & Not significant & \\
\hline B-pH & 0.2262 & Not significant & 0.0009 & Significant & \\
\hline $\begin{array}{l}\text { C- } \% \text { of } \\
\text { Acetonitrile }\end{array}$ & 0.5893 & Not significant & 0.6429 & Not significant & \\
\hline $\begin{array}{l}\text { D-Column } \\
\text { Temperature }\end{array}$ & $<0.0001$ & Significant & $<0.0001$ & Significant & $\begin{array}{l}\text { p should } \\
\text { be less }\end{array}$ \\
\hline$A D$ & 0.0442 & Significant & Not selected & NA & \\
\hline B2 & $<0.0001$ & Significant & Not selected & NA & \\
\hline D2 & Not selected & NA & 0.0113 & Significant & \\
\hline Model & $<0.0001$ & Significant & $<0.0001$ & Significant & \\
\hline Lake of Fit & 0.8665 & Not significant & 0.5576 & Not significant & \\
\hline
\end{tabular}

The response was plotted by changing only one factor over its range while holding all the other factors constant. The design space $\{$ Fig. 3(B) and (D)\} is the region in which changes to the method parameters will not significantly affect the results. During the experiment it was found that both of the responses are inversely proportional to each other, i.e. if Response-1 increases more than 6.5, Response-2 decreases less than 2, which was not advantageous. Hence, the criteria set to obtain the design space for Response-1 and Response-2 was the resolution between 3.2 to 6.5 and the resolution 2 to 4.5 , respectively.

\section{Conclusion}

The QbD-based reversed-phase HPLC method for the determination of impurities of omeprazole DDR was developed with a column containing a pellicular stationary phase. The method was evaluated in terms of specificity, linearity, and recovery. The CMPs were identified and applied to DOE, which displays the gruffness of the chromatographic method prior to validation. The method was found to be robust within the defined design space. This method is capable of achieving separation among omeprazole and its eleven related compounds in a short run time and is useful in the regions where regulatory agencies recommend HPLC over UPLC analytical methods.

However, the limit of detection and limit of quantification for all compounds need to be carried out in the future and the RRF establishment for Impurity-3, Impurity-10, and Impurity-11 needs to be executed further. The summary of the work advocates that this stability-indicating method is capable of achieving separation among omeprazole and its eleven related compounds in only 45 minutes.

\section{Acknowledgement}

The authors would like to thank the management of Dr. Reddy's Laboratories Ltd. for their valuable support and permission to carry out and publish the work. Authors also would like 
to thank all the colleagues and experts for their support during the development of the method and execution of the Experimental Design.

\section{Authors' Statement}

\section{Competing Interests}

The authors declare no conflict of interest.

\section{References}

[1] Snodin DJ, McCrossen SD.

Guidelines and pharmacopoeial standards for pharmaceutical impurities: overview and critical assessment. Regul.

Toxicol Pharmacol. 2012; 63: 298-312.

http://dx.doi.org/10.1016/j.yrtph.2012.03.016

[2] Singh S, Handa T, Narayanam M, Sahu A, Junwal M, Shah RP.

A critical review on the use of modern sophisticated hyphenated tools in the characterization of impurities and degradation products.

J Pharm Biomed Anal. 2012; 69: 148-173.

http://dx.doi.org/10.1016/j.jpba.2012.03.044

[3] Thakor AS, Burke A, Handfield-Jones S, Sinha A, Palmer M, Burns A.

Toxic epidermal necrolysis and neutropaenia: complications of omeprazole.

Australas J Dermatol. 2009; 50: 207-210.

http://dx.doi.org/10.1111/j.1440-0960.2009.00540.x

[4] Espinosa Bosch M, Ruiz Sánchez AJ, Sánchez Rojas F, Bosch Ojeda C.

Analytical methodologies for the determination of omeprazole: an overview.

J Pharm Biomed Anal. 2007; 44: 831-844.

http://dx.doi.org/10.1016/j.jpba.2007.04.022

[5] Trivedi HK, Patel MC.

Development and Validation of a Precise single HPLC Method for Determination of Omeprazole and its related compound in pharmaceutical formulation.

Int J Chem Tech Research. 2010; 2: 1355-1367.

[6] Nalwade SU, Reddy VR, Rao DD, Morisetti NK.

A validated stability indicating ultra performance liquid chromatographic method for determination of impurities in Esomeprazole magnesium gastro resistant tablets.

J Pharm Biomed Anal. 2012; 57: 109-114.

http://dx.doi.org/10.1016/j.jpba.2011.08.025

[7] Seshadri RK, Raghavaraju TV, Chakravarthy IE.

A Single Gradient Stability-Indicating Reversed-Phase LC Method for the Estimation of Impurities in Omeprazole and Domperidone Capsules.

Sci Pharm. 2013; 81: 437-458.

http://dx.doi.org/10.3797/scipharm.1209-12

[8] luga C, Bojita M, Leucuta SE.

Development of a Validated RP-HPLC Method for Separation and Determination of Process-Related Impurities of Omeprazole in Bulk Drugs.

Farmacia. 2009; 57: 534-541.

[9] Kormány R, Molnár I, Rieger HJ.

Exploring better column selectivity choices in ultra-high performance liquid chromatography using Quality by Design principles.

J Pharm Biomed Anal. 2013; 80: 79-88.

http://dx.doi.org/10.1016/j.jpba.2013.02.028 
[10] Monks K, Molnár I, Rieger HJ, Bogáti B, Szabó E.

Quality by Design: Multidimensional exploration of the design space in high performance liquid chromatography method development for better robustness before validation.

J Chromatogr A. 2012; 1232: 218-230.

http://dx.doi.org/10.1016/j.chroma.2011.12.041

[11] Flor S, Tripodi V, Scioscia S, Revello L, Lucangioli S.

Fast and Sensitive new HPLC-UV Method for Determination of Omeprazole and Major Related Substances in Pharmaceutical Formulation.

J Liq Chromatogr Relat Technol. 2010; 33: 1666-1678.

http://dx.doi.org/10.1080/10826076.2010.519232

[12] Lingam M, Reddy SA, Sinha V, Jogia HA, Arutla S, Pillai R, Gawande RS, Vure P, Vobalaboina V. Modified Release Benziimidazole Formulations.

2012, WO2012092486 A2.

[13] Omeprazole Monograph.

2010, European Pharmacopoeia. 7.0: 2621-2623.

[14] Omeprazole Monograph.

2013, British Pharmacopoeia.

[15] Kirkland JJ, Henderson JW, DeStefano JJ, van Straten MA, Claessens HA.

Stability of silica-based, endcapped columns with $\mathrm{pH} 7$ and 11 mobile phases for reversed-phase high-performance liquid chromatography.

J Chromatogr A. 1997; 762: 97-112.

http://dx.doi.org/10.1016/S0021-9673(96)00945-4

[16] Mathew M, Gupta VD, Bailey RE.

Stability of Omeprazole Solutions at Various pH Values as Determined by High-Performance Liquid Chromatography.

Drug Dev Ind Pharm. 1995; 21: 965-971.

http://dx.doi.org/10.3109/03639049509026660

[17] Kirkland JJ, Truszkowski FA, Ricker RD.

Atypical silica-based column packings for high-performance liquid chromatography.

J Chromatogr A. 2002; 965: 25-34.

http://dx.doi.org/10.1016/S0021-9673(01)01339-5

[18] http://www.chem.agilent.com/Library/datasheets/Public/820301-002.pdf (last seen 11-06-2013).

[19] http://www.interscience.nl/interscience/topics/accucore_brochure.pdf (last seen 11-06-2013). 